\title{
Follicular lymphoma of the duodenum
}

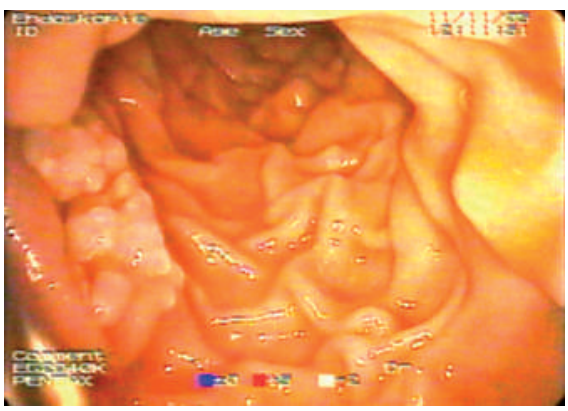

Figure1 Duodenal mucosa with whitish, coarsely lumped, polypoid raised areas, some of which are solitary, while others show a clustered arrangement.

Although the gastrointestinal tract is the most common site of manifestation of extranodal lymphomas, intestinal lymphomas as a whole are rare. Among these entities, follicular lymphomas are even rarer $[1-3]$ and show a female predominance [3].

We report the case of a 75-year-old woman who presented with cardiac arrhythmia. She also described nonspecific abdominal complaints.

To our surprise, at esophagogastroduodenoscopy of an otherwise normal-appearing duodenum, we found whitish, coarsely lumped, polypoid raised areas, some of which were solitary while others showed a clustered arrangement (Figure $\mathbf{1}$ )

Histopathology, including immunohistochemical studies [4], revealed follicular lymphoma grade 1 (Figure 2). Additional diagnostic procedures, such as computed tomography and bone marrow aspiration, showed no extraintestinal manifestation of the lymphoma.

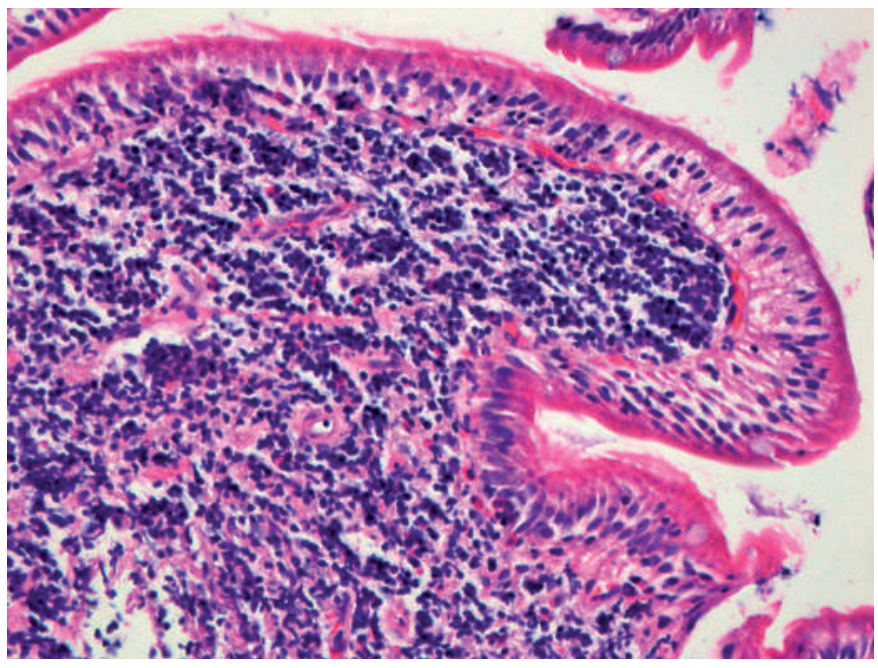

Figure 2 Follicular lymphoma of the duodenum with typical diffuse subepithelial infiltration by densely packed lymphocytes (hematoxylin and eosin stain; $\times 200$ ).

Double-balloon or capsule endoscopy [5] was not performed. Conventional intestinoscopy showed that all accessible areas of the duodenum and the first part of the jejunum were involved; however, the peripapillary area remained free. At ileocoloscopy, the terminal ileum was also seen to be free from disease

Following discussion of this case with several international experts, it was decided to refrain from any kind of special therapy and instead to observe the course of the disease, which was expected to be benign $[2,3]$.

Endoscopy_UCTN_Code_CCL_1AB_2AZ_3AB

\section{P. Born ${ }^{1}$, M. Vieth ${ }^{2}$, M. Stolte ${ }^{2}$}

${ }^{1}$ Abteilung für Innere Medizin, Kreiskrankenhaus Tirschenreuth, Germany

${ }^{2}$ Institut für Pathologie, Klinikum Bayreuth, Germany.

\section{References}

${ }^{1}$ LeBrun DP, Kamel OW, Cleary ML et al. Follicular lymphomas of the gastrointestinal tract. Pathologic features in 31 cases and bcl-2 oncogenic protein expression. Am J Pathol 1992; 140: 1327 - 1335

2 Poggi MM, Cong PJ, Coleman CN, Jaffe ES. Low-grade follicular lymphoma of the small intestine. J Clin Gastroenterol 2002; 34: $155-159$

${ }^{3}$ Damaj G, Verkarre V, Delmer A et al. Primary follicular lymphoma of the gastrointestinal tract: a study of 25 cases and a literature review. Ann Oncol 2003; 14: 623-629

${ }^{4}$ Chott A. Problems in biopsy differential diagnosis in lymphomas of the small and large intestines. Verh Dtsch Ges Pathol 1999; 83: $90-100$

${ }^{5}$ Flieger D, Keller R, May A et al. Capsule endoscopy in gastrointestinal lymphomas. Endoscopy 2005; 37: $1174-1180$

\section{Corresponding author}

\section{P. Born, MD}

Department of Internal Medicine County Hospital Tirschenreuth

St.-Peter-Str. 31

95643 Tirschenreuth

Germany

Fax: $\quad+49-89-41404905$

Email: peter.born@krankenhaustirschenreuth.de 